which follows well-tried lines in its manner of treatment, upon which much thought has evidently been spent in order to produce an up-to-date and accurate text-book. The early chapters give the methods and principles of chemistry and are followed by others dealing in detail with the nonmetallic elements and their compounds. The metals, about a dozen of which are described, are dismissed in sixty pages. Thus the book meets the requirements of those who wish to proceed further with chemistry and also of those who will discontinue the subject after leaving school. These latter should, however, be able to take away an impression of chemistry that will be of use in afterlife. For the teacher, this book has a convenient three-page index to experimental work in addition to a full general index.

G. D.

\title{
The Ways of the Weather
}

Weather Science for Everybody

By Prof. David Brunt. (Changing World Library.) Pp. xii $+170+6$ plates. (London: Watts and Co., 1936.) 2s. 6d. net.

A PTLY was meteorology described half a century ago as the "Cinderella of the Sciences": in those days it was a humble study indeed, attractive in the main only to amateurs and scorned by the majority of physicists. But Cinderella, as we know, could not be kept in the background; eventually she triumphed over her elder and more ambitious sisters. Is it to be the same with meteorology? From the utilitarian point of view the answer must surely be: Yes. Having regard, in particular, to the future development of weather forecasting and to the potentialities of stratospheric flight, it is indisputable that meteorology has the major part of a very important career still ahead.

Realization of this rather obvious fact seems to have come earlier to Germany, the United States and several other nations than to Great Britain. For here, and, indeed, throughout the entire Empire, there is still but one professorship of meteorology - at the Imperial College of Science and Technology, London. Prof. D. Brunt, who now holds that solitary post, is known to meteorologists all over the world for his valuable treatise "Physical and Dynamical Meteorology", first published in 1934. Having thus catered for the more learned brethren-those mathematical physicists who seek to solve the many obscure problems of the atmosphere-Prof. Brunt has wisely turned his energies to instructing the laity. Wisely, we say, because educational authorities, like business chiefs, are necessarily guided in the provision of their supply by consideration of the demand. If meteorology is to take its proper place among the sciences taught in our universities, there must be the requisite plea from the younger generation for facilities for tuition. This plea is most likely to be incited by popular books of the kind that Prof. Brunt has written.

The little work before us is one of the best of its type in the English language. Tersely, simply and unpretentiously, it sets forth as much of its subject as can be understood by the ordinary reader not at all heavily equipped with mathematical and physical training. Doubtless in the knowledge that many people have the habit of glancing at the beginning and end of a book before deciding to read it through, the author starts and finishes with chapters certain to have a wide appeal-"Weather and Human Affairs in Peace and War" and "How Climate and Weather Affect Health and Comfort". It is safe to say that few potential readers thus caught by Prof. Brunt's wiles will fail to follow him through the remaining twelve chapters. While all fourteen are meritorious, those on radiation and the world's climates may be singled out for special mention.

Among the occasional slips noted are a misleading account of the methods of infra-red photography, on p. 40, an erroneous specification (temperature for pressure) of the ordinates in the diagram on p. 98, and the assertion on pp. 142-143 that the winters from $1930-31$ to $1935-36$ were all fairly mild in London. Actually, the winter of 1933-34 was the third coldest of the present century at Greenwich Observatory, with a mean temperature about $2^{\circ} \mathrm{F}$. below the average. Surely, too, the English spring repeatedly refutes Prof. Brunt's statement on p. 65 that "snow can reach the ground only when the temperature even at the ground is down to freezing-point, or at most a degree or two above it". There are numerous records of true snow-flakes (as distinct from soft hail) having been observed during March and April on occasions when the surface air-temperature exceeded $40^{\circ} \mathrm{F}$.

In view of its modest price, Prof. Brunt's book is very well produced and most generously illustrated, not only with line-diagrams but also with several excellent photographs. E. L. Hawke. 